\title{
GRASSHOPPER IDENTIFICATION AND CONTROL METHODS TO PROTECT CROPS AND THE ENVIRONMENT
}

Dan L. Johnson. 2008. Published by the Saskatchewan Pulse Growers, and Agriculture and Agri-Food Canada, Pesticide Risk Reduction Program, Pest Management Centre, Ottawa. 42 pp.

To spray or not to spray? That is the question Dan Johnson tries to help farmers decide when they find grasshoppers in their pulse crops.

Through the use of photographs for identification of grasshopper species, descriptions of life history and biology, and general assessments of the potential of various grasshopper species to damage a crop, the author helps the pulse farmer evaluate the potential of a grasshopper infestation to damage his crop and his need to take control action. Although this publication is primarily a management tool, it is also an introduction to the surprisingly diverse field of grasshopper biology.

The prairies are "blessed" with a greater variety of true grasshoppers (approximately 80 species, members of the family Acrididae, the short-horned grasshoppers) than comparable regions of Canada such as British Columbia or Ontario. Prairie people are aware of the pivotal role grasshoppers play in their environment, and may even take pride in their grasshoppers, whether it be shown as fear from the devastation of a pestilence, or as the subject of legend and humour. However, Johnson shows us that the general concept of "grasshoppers" is actually too broad to be very useful. There are many different species of grasshoppers, and for each, several factors such as the developmental stage, habitat, and behaviour must be considered when talking about its potential for crop damage.

Only three of the 80 or so species of true grasshoppers that occur on the prairie are serious pests of pulse crops. Another seven species are ranked as having low pest status (although they may be serious pests of grasses), and the remainder of the fauna is considered neutral or beneficial. The concept of a beneficial grasshopper may sound surprising, but a number of species are specialists that feed on only one or a small group of plants (usually those that we would consider weedy species). Other grasshopper species occur on land that is agriculturally marginal or unsuitable, or they almost constantly occur in low enough numbers that they never pose a pest problem.

There are a few simple rules that can quickly identify the majority of non-pest species. A grasshopper is not a pulse pest if any of these conditions apply: adults occur in early spring before June; the hind wings are distinctly coloured with yellow, red, dark blue, or black; the adult grasshopper sings, clacks, or clatters either in flight or while sitting on the ground; the face in profile is pushed in (slant-faced) so that the bases of the antennae occur in front of the level of the mouth; and/or there is no distinct bump or spur ("Adam's apple"- like structure) between the bases of the front legs (as one exception, the range grasshopper 


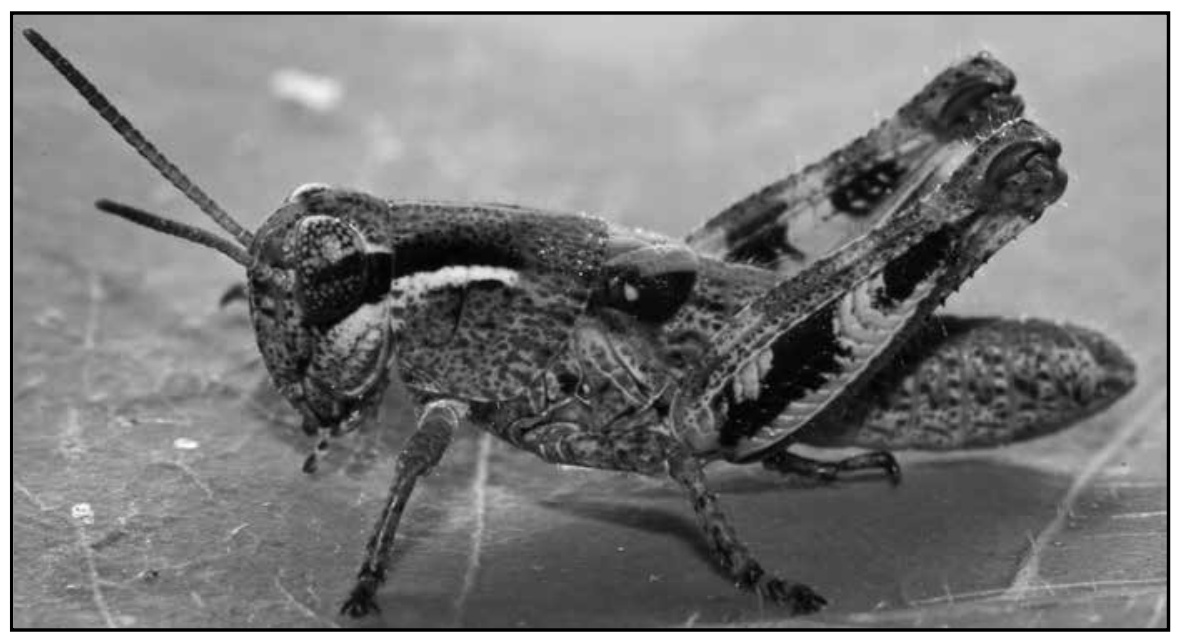

Melanoplus sp., possibly a fourth-instar nymph of Bruner's spur-throat grasshopper (M. bruneri).

Harvey Schmidt

Camnula pellucida is considered of low pest status).

This book will no doubt be very useful to the pulse grower who would like to make a quick assessment of whether a grasshopper problem is developing. But it also has a wider role in introducing the general public to an unexpectedly diverse group of usually taken-for-granted insects. Besides the economic rewards of learning to identify grasshoppers, there are the satisfactions and surprises of learning about the habitat selection, feeding preferences, and behavioural peculiarities of these insects. This book is a fine introduction into this world. For those stimulated to deeper studies of grasshoppers, two very useful books are available: Vickery \& Kevan (1985) ${ }^{1}$ and Capinera et al. (2004). ${ }^{2}$

The photographs in the book show the array of forms, colours, and patterns displayed by prairie grasshoppers. This may be an inspiration for other naturalist photographers. Grasshopper photography has many rewards, especially in terms of learning the diverse biology of these insects as well as challenges in capturing the bright colors (often confined to the legs and wings and usually hidden from prying eyes and camera lenses) and behavioural displays.

The practical lesson Johnson provides is that only after we have determined the species and its general potential to cause damage to a given type of crop, its developmental stage, and its abundance, should we make the decision - let us spray.

1. Vickery VR, Kevan DKM (1985) The Insects and Arachnids of Canada, Part 14. The Grasshoppers, Crickets, and Related Insects of Canada and Adjacent Regions. Research Branch, Agriculture Canada, Publication 1777. Ottawa, ON.

2. Capinera JL, Scott RD, Walker TJ (2004) Field Guide to Grasshoppers, Katydids, and Crickets of the United States. Cornell University Press, Ithaca, NY.

- Reviewed by David Larson, PO Box 56, Maple Creek, SK SON 1NO; E-mail: <dmlarson@sasktel.net>

Editors' note: For an on-line version of this book, see <http://www.saskpulse. com/media/pdfs/2008_Grasshopper_ Identification_Booklet.pdf >. 